\title{
O ensino colaborativo como possibilidade para a promoção de práticas pedagógicas em um contexto educacional inclusivo
}

\author{
Betina Weber de Souza ${ }^{1}$ \\ Franciele Rusch König² \\ Fabiane Romano de Souza Bridi ${ }^{3}$
}

\begin{abstract}
Resumo:
O presente texto configura-se como um relato de experiência, e emerge de ações pedagógicas pertinentes à educação inclusiva desenvolvidas na educação básica. Tem como objetivo relatar experiências teórico-práticas de ensino colaborativo por meio do Programa Institucional de Bolsas de Iniciação à Docência-PIBID/Educação Especial, com ênfase nos anos finais do ensino fundamental. A experiência que fomenta o escrito derivou-se da colaboração de uma bolsista pibidiana, acadêmica de educação especial, com docentes de uma escola da rede pública de ensino, contemplando parceria no planejamento, desenvolvimento das propostas e avaliação, característica central do ensino colaborativo. Destaca-se a potência da proposta desenvolvida como alternativa para a qualificação das possibilidades de escolarização e aprendizagem de todos os estudantes, favorecendo a disponibilização de estratégias e recursos do Atendimento Educacional Especializado no contexto da sala de aula. Ainda, oferece subsídios teórico-práticos para a formação docente inicial, continuada, e em serviço, contribuindo para o desenvolvimento de práticas pedagógicas articuladas e pertinentes a um cenário educacional inclusivo.
\end{abstract}

\section{Palavras-chave:}

Ensino colaborativo. Práticas pedagógicas. Educação inclusiva.

\footnotetext{
1 Especialista em Gestão Educacional pela Universidade Federal de Santa Maria (UFSM) e estudante de Neuropsicopedagogia na Faculdade Censupeg. Professora de Educação Especial (Sala Multimeios) na Rede Municipal de ensino de Florianópolis. E-mail: betinaweber28@gmail.com. ORCID iD: https://orcid.org/0000-0003-3106-0674.

2 Doutoranda em Educação pela Universidade Federal de Santa Maria (UFSM) e professora de Educação Especial. E-mail: fraan. konig@gmail.com. ORCID iD: https://orcid.org/0000-0002-3245-8257.

3 Doutora em Educação. Professora do Departamento de Educação Especial e do Programa de Pós-Graduação em Educação da Universidade Federal de Santa Maria (UFSM) .E-mail: fabianebridi@gmail.com. ORCID iD: https://orcid.org/0000-0002-8727-851X.
} 


\title{
Collaborative teaching as a possibility to promote pedagogical prac- tices in an inclusive educational contexto
}

\begin{abstract}
:
This text is configurated as an experience report, and emerges from pedagogical actions pertinent to inclusive education developed on basic education. It aims to report theoretical-practical experiences of collaborative teaching by the Institutional Program of Scholarships for beginner teachers - PIBID/Special Education, with emphasis on an elementary school. The experience that fosters this writing comes from the collaboration of a scholarship person who is also an undergraduate student in the Special Education course and a member from the program, with teachers from a public school, contemplating partnership on planning, development of proposals and evaluation - the central characteristic of collaborative teaching. It was highlighted the power of the proposal developed as an alternative to the qualification of possibilities of schooling and learning of all students, favoring the provision of strategies and resources of the special education service in the context of the classroom. Yet, it offers theoretical-practical subsides to the initial, continued, and in-service teacher formation, contributing to the development of pedagogical practices articulated and pertinent to an inclusive educational service.
\end{abstract}

Keywords:

Collaborative teaching. Pedagogical practices. Inclusive education.

\section{La educación colaborativa como posibilidad de promoción de prácticas pedagógicas en un contexto educativo inclusivo}

Resumen:

Este texto es un relato de experiencia y surge de acciones pedagógicas relevantes para la educación inclusiva desarrolladas en la educación básica. Tiene como objetivo reportar experiencias teórico-prácticas de docencia colaborativa a través del Programa Institucional de Becas de Iniciación Docente-PIBID/Educación Especial, con énfasis en los últimos años de la escuela primaria. La experiencia que fomenta la escritura se derivó de la colaboración de un estudiante con beca de estudio y académica del curso de educación especial, juntamente con profesores de una escuela pública, contemplando la asociación en la planificación, desarrollo de propuestas y evaluación, característica central de la enseñanza colaborativa. Se destaca la potencia de la propuesta desarrollada como alternativa para la calificación de las posibilidades de escolarización y aprendizaje de todos los estudiantes, favoreciendo la disponibilidad de estrategias y recursos del Servicio Educativo Especializado en el contexto del aula. Además, ofrece apoyo teórico y práctico para la formación docente inicial, continua y en servicio, contribuyendo al desarrollo de prácticas pedagógicas articuladas y pertinentes en un entorno educativo inclusivo.

Palabras clave:

Enseñanza colaborativa. Prácticas pedagógicas. Educación inclusiva.

\section{Introdução}

Em consonância com os movimentos em prol da educação inclusiva e contribuindo com a emergência da defesa das possibilidades de acesso, permanência e aprendizagem dos alunos público-alvo da educação especial nas instituições de ensino regular, este texto objetiva relatar 
experiências teórico-práticas de ensino colaborativo por meio do Programa Institucional de Bolsas de Iniciação à Docência-PIBID/Educação Especial.

A partir dos anos 2000, houve uma significativa ampliação das discussões e ações, em âmbito nacional, pertinentes à organização da educação especial em uma perspectiva inclusiva, garantindo o acesso dos estudantes com deficiência, transtornos globais do desenvolvimento e altas habilidades/ superdotação nas escolas de ensino comum. Em consonância com movimentos internacionais, são criados e fortalecidos programas de formação de professores, inserção de disciplinas vinculadas à educação inclusiva nos cursos de licenciatura e implantação de salas de recursos multifuncionais nas escolas. Tais estratégias compunham um conjunto de ações para qualificar as possibilidades de escolarização e aprendizagem de todos, em uma perspectiva da educação inclusiva.

Potencializada a garantia de acesso aos sistemas escolares comuns de todos os sujeitos em idade escolar, os movimentos de professores e pesquisadores são direcionados para as possibilidades de permanência e aprendizagem nas classes comuns dos alunos público-alvo da educação especial e de todos os estudantes. Dentre diversas perspectivas, estudos são direcionados às possibilidades de articulação entre professor de educação especial e professor de ensino comum, conforme previsto nos documentos legais que orientam e normatizam a educação especial e o atendimento educacional especializado, seu principal serviço. (BRASIL, 2008; BRASIL, 2009).

Em defesa dessa articulação, e a partir do reconhecimento de sua potência para a qualificação das possibilidades de escolarização e aprendizagem dos estudantes público-alvo da educação especial, contemplaremos neste relato um recorte mais específico pertinente ao conceito de ensino colaborativo, por meio de ações do Programa Institucional de Bolsas de Iniciação à Docência PIBID/UFSM/Educação Especial.

Através do referido programa, bolsistas de educação especial desenvolveram ações em escolas da rede regular de ensino do município de Santa Maria com um trabalho estruturado sob três eixos: realizar o atendimento individualizado com um aluno do público-alvo da educação especial; trabalhar de forma articulada com seus professores na classe comum, orientando sobre a perspectiva de ensino colaborativo; confeccionar/adaptar materiais pedagógicos para uso tanto na sala de recursos quanto na classe regular.

Ao considerar essa proposta como um marco importante na formação de professores de classe comum e professores de educação especial, bem como para que se continue expandindo os princípios do ensino colaborativo entre professores que já se encontram dentro de classes regulares e, especialmente, com alunos que fazem parte do público-alvo da educação especial, este escrito direciona-se ao relato das ações desenvolvidas no contexto do PIBID, em uma perspectiva do ensino colaborativo.

A experiência foi desenvolvida em uma turma de nono ano, em decorrência do encaminhamento de um estudante de quinze anos, chamado neste capítulo de Artur ${ }^{4}$, ao atendimento pelo programa. Artur foi encaminhado por apresentar um quadro de deficiência intelectual, decorrente de uma meningite na infância e frequentava o Atendimento Educacional Especializado no contraturno.

\section{Práticas pedagógicas articuladas: a proposta do ensino colaborativo no contexto dos anos finais do ensino fundamental}

O ensino colaborativo configura-se por uma possibilidade organizacional das práticas pedagógicas desenvolvidas em uma perspectiva inclusiva, que prevê a articulação - em equidade de responsabilidades - entre o professor de educação especial e o professor do ensino comum, nas dimensões do planejamento, desenvolvimento e avaliação. Tem como objetivo possibilitar a

4 Nome fictício, para preservar a identidade do estudante. 
interlocução entre professores de classes regulares de ensino e professores de educação especial, bem como deslocar para a sala de aula comum os recursos e as estratégias educacionais dos quais necessitam os estudantes público-alvo, contribuindo para a melhoria dos processos educacionais da turma toda. (MENDES; VILARONGA; ZERBATO, 2014).

Lago (2014), ao discorrer acerca da dinamicidade do ensino colaborativo, aborda três fases do estabelecimento da parceria entre o professor do ensino comum e o professor da educação especial: fase inicial, fase intermediária e fase final. $\mathrm{Na}$ fase inicial, embora exista uma articulação no trabalho, ainda não há uma ação colaborativa entre os dois professores, constituindo dois modelos de parceria: em um deles, um professor ensina e o outro observa e, no outro, um professor responsabiliza-se pela condução das atividades e o outro se coloca no papel de auxiliar.

A fase intermediária constitui três maneiras de parceria: o ensino paralelo, no qual a turma é dividida em dois grupos e cada professor responsabiliza-se por um deles, de modo a conduzir as mesmas atividades; as estações de ensino, que preveem a divisão da turma em grupos por níveis de aprendizagem, com circulação dos professores; e o ensino alternativo, no qual um professor responsabiliza-se por um grupo com objetivos específicos e o outro assume o restante dos estudantes, dividindo-os em grupos de trabalho. Nesta fase, ainda não é estabelecida uma colaboração efetiva nas dimensões do planejamento, desenvolvimento e avaliação das práticas pedagógicas.

$\mathrm{Na}$ fase final, efetiva-se um modelo de parceria que caracteriza o que compreendemos por ensino colaborativo, havendo divisão de responsabilidades. Nesta fase, os professores planejam, desenvolvem e avaliam as práticas de maneira colaborativa, com equidade nas responsabilidades.

Considerando o aspecto dinâmico desta proposta, diferentes níveis de parceria podem ser estabelecidos a depender da objetividade da proposição, sendo consideradas as necessidades e características dos estudantes, a demanda curricular, além do espaço físico e intervalo de tempo disponível (CAPELLINI, 2004). A articulação do trabalho colaborativo poderá atingir diferentes fases e transitar por distintas formas de parceria, não havendo a necessidade de uma evolução linear entre as fases.

Nos anos iniciais do ensino fundamental, do primeiro ao quinto ano, as classes regulares estão sob a regência de um único professor. São eles que, em um primeiro momento, observam os processos de aprendizagem e os níveis de compreensão dos seus alunos. A interlocução para um trabalho colaborativo deve ocorrer, nesses casos, entre o professor da classe regular e o professor de educação especial.

Nos anos finais do ensino fundamental, a organização de um trabalho articulado entre educação especial e ensino comum assume características diferentes daquelas observadas nos anos iniciais, marcados pela unidocência. Nas turmas do sexto ao nono ano, a grade curricular é composta basicamente por dez disciplinas (Língua Portuguesa, Matemática, História, Geografia, Ciências, Artes, Língua Inglesa, Língua Espanhola, Ensino Religioso e Educação Física), o que implica um número elevado de professores para a articulação com o professor de educação especial, bem como um contingente de conteúdos vinculados às diferentes áreas do conhecimento. Nesses casos, ainda que a realização do trabalho colaborativo ocorra de forma mais pontual em cada disciplina, existe a necessidade de uma articulação entre toda a equipe de professores, considerando que constituem uma rede de atuação responsável pela construção dos conhecimentos pelos estudantes.

Assim, na turma em que foi desenvolvida a proposta, o principal desafio dos professores consistia em desenvolver atividades capazes de envolver os estudantes, tendo em vista que se dispersavam dos conteúdos escolares com facilidade frente a assuntos pertinentes aos interesses na adolescência. O telefone celular era uma distração quase incontrolável para os alunos e, mesmo que já houvesse um vínculo afetivo entre a maioria deles, por estarem na mesma turma há anos, aconteciam, durante as aulas, muitos confrontos entre eles.

Por esse motivo, muitos professores demonstravam anseios por práticas que despertassem o interesse dos alunos, que fizessem com que os conteúdos complexos ficassem mais acessíveis e 
que, principalmente, tornassem os alunos mais atentos e dispostos às atividades propostas. Alguns, inclusive, tentaram inserir em suas aulas atividades dinâmicas, que envolviam elementos presentes no cotidiano dos alunos.

A turma, de um modo geral, demonstrava dificuldades nos processos abstracionais, em especial, os vinculados ao raciocínio lógico-matemático. Assim, embora a indicação ao acompanhamento pelo PIBID fosse justificada por dificuldades acentuadas nos processos de aprendizagem do estudante Artur, a turma apresentava um perfil semelhante, desafiando as proposições metodológicas dos professores. A presença da bolsista como apoio às demandas, contribuiu para que alguns professores permitissem as primeiras aproximações e passassem a desejar a organização de propostas em articulação.

Os desafios eram vivenciados por todos os professores da turma e, ao considerar que eram dez disciplinas e pensar em como articular práticas com todos os professores, também se configurava como um desafio para a bolsista. Alguns professores mostravam-se mais abertos e dispostos ao diálogo do que outros, e foi com esses que a proposta de colaboração alcançou parcerias mais consolidadas.

Destaca-se que o estabelecimento de uma prática colaborativa não ocorre de maneira rápida, exigindo de ambos os profissionais a confiança, o respeito, o profissionalismo, a voluntariedade e a disponibilidade ao diálogo, visto que é praticamente inevitável o confronto de diferentes concepções. São necessários tempo e prática para que se construa uma relação de confiança, fundamental ao trabalho colaborativo (CAPELLINI, 2004). Dessa forma, dos dez professores responsáveis pelos processos de aprendizagem da turma, a articulação se deu com quatro (Ensino Religioso, Língua Portuguesa, Língua Inglesa e Ciências), contemplando com cada um deles pelo menos duas atividades.

As propostas iniciais foram articuladas com a professora de Ensino Religioso, com o objetivo de promover um momento de interação na turma. A atividade foi planejada pela bolsista e teve o desenvolvimento conduzido em parceria com a professora, configurando a fase inicial do ensino colaborativo. Buscando maior integração no grupo, cada integrante - estudantes, bolsista e professora - deveria escrever suas características e seus sonhos em uma folha branca sem identificação. As folhas foram distribuídas aleatoriamente na turma, de modo que ninguém recebesse a própria ficha, e o desafio consistiu em tentar descobrir o autor da escrita a partir das informações registradas.

A possibilidade de reconhecer o colega e tornar legítimo o seu jeito de ser, seus sonhos e seus desafios, despertou entre os estudantes um respeito ao espaço, aos desejos e argumentos do outro. Reforçou um laço de parceria e amizade, por vezes, esquecidos, em meio aos debates tensionados durante as aulas.

A partir dessa avaliação feita entre a bolsista e a professora, as proposições foram direcionadas para atividades desenvolvidas em colaboração, construídas em grupo. Historicamente, a construção do conhecimento humano caracteriza um processo social, potencializado a partir das relações que os sujeitos estabelecem através da linguagem, tendo em vista um objetivo. Não se trata de um processo individual, mas de uma construção sociocultural a ser internalizada pelos sujeitos (VYGOTSKY, 1991). Neste viés, as atividades pedagógicas desenvolvidas em articulação com o ensino comum estiveram balizadas na premissa de que o trabalho grupal, na medida em que favorece os processos interacionais, configura como um potente elemento qualificador da construção de novos conceitos pelos estudantes.

Dessa forma, o planejamento com os outros professores ganhou um objetivo comum. As proposições, de modo geral, almejavam o acesso aos conteúdos de maneira interativa, dinâmica e com elementos concretos para a melhor compreensão, mas, para além disso, também estavam alicerçados no trabalho em grupo, na construção coletiva da aprendizagem.

Dentre estas proposições com a professora de Ciências, a construção de uma tabela periódica interativa encontra-se em destaque. A proposta emergiu dos conteúdos de aula, que envolviam os elementos da tabela periódica, seus grupos e famílias. Frente às dificuldades na interação com 
o conteúdo apresentadas pela turma, os estudantes foram convidados a construírem uma tabela periódica interativa, a partir do material de um banner descartado, com a confecção dos elementos em quadrados de E.V.A e fixados na tabela com velcro, respeitando a organização original. A tabela construída passou a integrar as aulas seguintes, constituindo um dos principais recursos utilizados pela professora.

Dessa forma, além do fortalecimento do trabalho coletivo, a proposta ofertou aos estudantes a possibilidade de contarem com um recurso interativo para uso comum nas aulas de Ciências. A participação de todos na construção possibilitou que o trabalho abandonasse o formato abstrato e tomasse uma forma concreta, além de envolver a todos durante o processo de confecção.

Em articulação com a professora de Língua Portuguesa, outra proposta ganhou evidência pelo interesse e pela participação dos alunos. Frente ao conteúdo a ser abordado em sala de aula e buscando alternativas para melhor vinculação e compreensão dos estudantes, a atividade propôs o trabalho com figuras de linguagem a partir de músicas ouvidas cotidianamente pela turma.

Inicialmente, foi solicitado aos alunos que escrevessem letras de músicas que eles gostassem e entregassem para a professora ou para a bolsista. A professora de Língua Portuguesa destacou as figuras de linguagem identificadas nas letras e, com o auxílio da bolsista, elaborou perguntas sobre elas. $\mathrm{Na}$ aula seguinte, os alunos foram divididos em grupos e deveriam, após jogar um dado de cores, escolher um envelope na cor sorteada para responder a que figura de linguagem o fragmento de música contida no envelope correspondia.

O trabalho com conteúdos específicos de Língua Portuguesa, de forma lúdica, favoreceu a vinculação da turma com a matéria e qualificou a compreensão acerca das figuras de linguagem. Durante o desenvolvimento da atividade, os alunos estavam descontraídos e brincavam com as possibilidades para outras músicas, demonstrando um interesse por ir além do que estava sendo apresentado na atividade. Na medida em que respondiam à tarefa com a ajuda da professora, também questionavam sobre outros trechos de músicas, indicando interesse e compreensão sobre o conteúdo.

Assim, além de alcançar o objetivo maior, que diz respeito ao acesso à aprendizagem de forma dinâmica, pensando nas características de todo o grupo, a atividade também trouxe um caráter de construção coletiva da aprendizagem, identificado pelos professores como uma necessidade da turma.

Com a professora de Língua Inglesa, a proposta em articulação a ser destacada foi a da realização de um Quiz sobre os verbos. O objetivo principal era retomar com os alunos os verbos trabalhados pela professora durante $\mathrm{o}$ ano através de uma experiência divertida e de interação entre eles. A turma foi dividida em grupos e a cada rodada todos os grupos jogavam um dado colorido e recebiam uma pergunta retirada de um envelope na cor sorteada. Quem jogava o dado poderia responder à pergunta de forma individual (dando ao grupo três pontos), com a ajuda do grupo (dando a eles dois pontos) ou com o auxílio do dicionário (somando para o grupo um ponto). Ao final, o grupo vencedor foi aquele que somou mais pontos.

De uma forma dinâmica e prazerosa, os estudantes realizaram a retomada de um importante elemento da disciplina, qualificaram os laços e mobilizaram novas aprendizagens na interação grupal desencadeada por um elemento lúdico. Na execução das práticas articuladas, por meio da diversificação das estratégias metodológicas, conteúdos que eram desafiadores aos estudantes por sua complexidade e exigência de alto nível abstracional, puderam ser compreendidos por todos, contemplando o objetivo de cada uma das disciplinas. Assim, reitera-se a potência da articulação entre educação especial e ensino comum na elaboração de práticas pedagógicas em um contexto inclusivo, como proposta qualificadora das possibilidades de aprendizagem de todos os estudantes, na interação entre colegas e por meio de propostas diversificadas. 


\section{Algumas considerações pertinentes}

Práticas pedagógicas em articulação configuram-se como uma ferramenta potente no que tange aos processos de ensino e aprendizagem, especialmente dentro de classes regulares de ensino. Entretanto, para que se desenvolva uma proposta em articulação, é necessário minimamente que se estabeleça uma relação de confiança e de divisão das responsabilidades entre os professores.

Em razão da demanda que circunda a articulação de práticas pedagógicas com um grupo de professores, é possível observar que todas as propostas realizadas não contemplaram um momento específico para planejamento e para avaliação. Os planejamentos, de modo geral, foram realizados a partir de uma ideia inicial da bolsista e organizados durante intervalos de aulas ou através da troca de e-mails. Da mesma forma, as avaliações se deram majoritariamente pelas professoras da turma, com a troca rápida de observações e considerações com a bolsista, realizadas entre uma aula e outra.

Entretanto, é preciso ressaltar a pluralidade de ideias, de conhecimentos, de possibilidades existentes na troca entre professores. A possibilidade de pensar estratégias se torna ainda maior quando estas configuram-se como resultado da soma de conhecimentos, de habilidades, de percepções, de experiências. Do mesmo modo, as responsabilidades quando divididas tornam a atuação mais prazerosa, mais aberta a novas possibilidades e, especialmente, mais possíveis de execução.

$\mathrm{O}$ ano acabou e as possibilidades de estratégias naquela turma também. Professores, alunos e bolsista seguiram conforme seus objetivos, mas as trocas vivenciadas como pertencentes a um único grupo formaram uma pluralidade de experiências de aprendizagem que farão a diferença no processo de formação de cada um. E pensar no processo de aprendizagem como algo dinâmico, no contexto de sala de aula como espaço para o desafio, a troca de ideias e a diversão, transforma a escola em um lugar de encontros prazerosos com amigos, professores e, especialmente, com o conhecimento.

\section{Referências}

BRASIL. MEC/CNE. Resolução $N^{o} 4$, que Institui diretrizes operacionais para o Atendimento Educacional Especializado na Educação Básica, modalidade Educação Especial. Brasília, DF, 2009.

BRASIL. MEC/CNE. Política Nacional de Educação Especial na Perspectiva da Educação Inclusiva. Brasília: MEC/ SECADI, 2008

CAPELLINI, Vera Lúcia Messias Fialho. Avaliação das possibilidades do ensino colaborativo no processo de inclusão escolar do aluno com deficiência mental. 2004. 302 f. Tese (Doutorado em Ciências Humanas) - Universidade Federal de São Carlos, São Carlos, 2004.

LAGO, Danúsia Cardoso. Atendimento Educacional Especializado para alunos com deficiência intelectual baseado no coensino em dois municípios. São Carlos: UFSCar, 2014.

MENDES, Enicéia Gonçalves; VILARONGA, Carla Ariela Rios; ZERBATO, Ana Paula. Ensino Colaborativo como apoio à inclusão escolar. São Paulo: Edufscar, 2014.

VYGOTSKY, Lev Semenovich. A formação social da mente: o desenvolvimento dos processos psicológicos superiores. São Paulo: Martins Fontes, 1991.

Data de submissão: 14/05/2021

Data de aceite: $29 / 06 / 2021$ 